\title{
Secondary Structure-Induced Micro- and Macrophase Separation in Rod-Coil Polypeptide Diblock, Triblock, and Star-Block Copolymers
}

\author{
Antoni Sánchez-Ferrer ${ }^{\dagger, *}$ and Raffaele Mezzenga ${ }^{*},+*$ \\ †Department of Physics and Fribourg Center for Nanomaterials, University of Fribourg, Chemin du Musée 3, \\ CH-1700 Fribourg, Switzerland. New address: ETH Zurich, Food \& Soft Materials Science, Institute of Food \\ Science \& Nutrition, Schmelzbergstrasse 9, LFO, E23, 8092 Zürich, Switzerland
}

\begin{abstract}
Ten novel rod-coil block copolymers based on poly( $\gamma$-benzyl-L-glutamate) (PBLG), rod block, and poly(propylene oxide) (PPO), coil block, have been synthesized, and the influence on their secondary structure and solid-state organization have been studied in terms of their architecture (diblock, triblock, or star-block), molecular weight of the polymer coil block (from 2 to $5 \mathrm{kDa}$ ), and volume fraction of the rod block ( 0.50 or 0.75$)$. The degree of polymerization of the polypeptide segment into the arms of the block copolymers, $\mathrm{DP}_{\text {arm }}$, strongly affects the final $\alpha$-helical secondary structure and the corresponding self-assembling of the block copolymers. Below 20 amino acid residues, a mixture of secondary structures ( $\alpha$-helices, $\beta$-sheets, and unordered segments) and microphase separation of the blocks is present. Above 20 repeating units, the microphase separation goes together with macrophase separation of the pure $\alpha$-helical secondary structure, which ends up into an orthogonal lamellar phase or rods.
\end{abstract}

\section{Introduction}

Rod-coil block copolymers differ substantially from the common coil-coil block copolymers in their solid-state selforganization. The presence of a rodlike block induces essentially two specific features: a high conformational asymmetry in the phase diagram and liquid-crystalline interactions among the rigid blocks. ${ }^{1}$ These differences, which have been rationalized both theoretically $^{1-4}$ and experimentally, ${ }^{5-9}$ became more evident when the rodlike block occupies the greatest part of the overall volume fraction in the system. Traditionally, the study of rod-coil block copolymers has been carried out on two main classes of systems: those on which the rodlike block is embodied by a $\pi$-conjugated polymer ${ }^{10-14}$ and those in which this block is constituted by a polypeptide ${ }^{15-18}$ or other polymer ${ }^{5,19}$ exhibiting a helical secondary structure. More recently, a rod-coil pseudobehavior has also been shown in coil-coil block copolymers in which one of the two blocks is highly stretched by bulky pendant side groups. $^{20,21}$

With respect to the work carried out on the synthesis of peptide-based block copolymers, special attention was given to the synthesis and study of the influence of the nonpeptide block chemistry into the peptide block organization. ${ }^{22}$

The most commonly studied polypeptide is poly $(\gamma$-benzylL-glutamate) (PBLG), which shows rodlike organization because of the formation of $\alpha$-helices as secondary structure. For the nonpeptide block, semicrystalline, amorphous, hydrophilic, hydrophobic, and $\pi$-conjugated polymers, for example, poly(ethylene oxide) (PEO), ${ }^{23,24}$ poly( $N$-isopropylacrylamide) (PNIPAM $),{ }^{25}$ poly(dimethylsiloxane) (PDMS), ${ }^{26}$ poly(styrene) (PS), ${ }^{27}$ poly(butadiene) (PB), ${ }^{28}$ poly(isoprene) (PI), ${ }^{29}$ or poly(fluorine) (PF), have been used so far as macroinitiators. One of the most interesting properties of the resulting materials is the biocompatibility and biodegradability of the PBLG block when deprotected

\footnotetext{
*To whom the correspondence should be addressed. E-mail: raffaele. mezzenga@unifr.ch.
}

and the formation of hydrogels for drug delivery ${ }^{31}$ that are $\mathrm{pH}-$ and temperature-sensitive. ${ }^{32,33}$

In this article, new amino end-functionalized polymers with one, two, or three (in a three-arm star configuration) reactive amino groups have been used for the synthesis of novel di-, tri-, and tetra-block copolymers. The polymer selected as the flexible block is based on poly(propylene oxide) (PPO) ${ }^{34}$ which has a low glass transition temperature, $T_{\mathrm{g}} \approx-60$ to $-70{ }^{\circ} \mathrm{C}$, and is completely amorphous, allowing a perfect coil conformation. These amino-terminated polymers were reacted with the $\gamma$-benzyl L-glutamate $N$-carboxyanhydride (BLG-NCA) leading to the synthesis of the corresponding multiblocks. By controlling parameters such as the architecture of the polymer melt (linear or starlike), its molecular weight, and the volume fraction of the polypeptide block, the final block copolymers exhibit different self-assembly behaviors.

We present a complete study spanning from the control of the chemistry to the formation of the secondary structure of polypeptide block to the self-organization and liquid-crystallinity behavior of the different molecular architectures. We investigate ten different block copolymer systems but limit the study to high volume fractions of the PBLG block ( $\geq 50 \%$ ), for which a perfect lamellar organization, at least on the diblock configuration, ${ }^{1}$ would be expected. In particular, we show that the two fundamental parameters that control the final self-assembly scheme are: (i) the degree of polymerization (DP) of the PBLG blocks, which determines the secondary structure and the final organization of the microphase-separated system, and (ii) the polydispersity index (PDI) of the resulting block copolymers, which can induce a partition into the different secondary structures of the PBLG block, leading to macrophase separation mechanisms of the final block copolymers.

\section{Experimental Part}

Materials. L-Glutamic acid $\gamma$-benzyl ester (Fluka, $\geq 99.0 \%$ ), triphosgene (Aldrich, 98\%), N,N-dimethylformamide (DMF) (Sigma-Aldrich, $\geq 99.8 \%$, over molecular sieve), methylene chloride 
(DCM) (Acros, 99.99\%), and methanol (Fluka, 99.8\%) were used as received. Ethyl acetate (Sigma-Aldrich, $\geq 99.9 \%$ ) and cyclohexane (Sigma-Aldrich, $\geq 99.9 \%$ ) were dried and distilled over $\mathrm{CaH}_{2}$ (Fluka, $>97.0 \%$ ) at normal pressure. Mono-, di-, and triamine-terminated poly(propylene oxide)-based macroinitiators Jeffamine M-2005, D-2000, D-4000, T-3000, and T-5000 (Jeffamines), with approximate number average molecular masses of 2000, 2000, 4000, 3000, and $5000 \mathrm{~g} \cdot \mathrm{mol}^{-1}$, respectively, were kindly provided by Huntsman Corporation and degassed before use.

Monomer Synthesis. $\gamma$-Benzyl L-glutamate $N$-carboxyanhydride (BLG-NCA) was synthesized with some modifications according to previously published methods where water washing $^{35}$ and rephosgenation ${ }^{36}$ were avoided. In a $500 \mathrm{~mL}$ twonecked round-bottomed flask equipped with a magnetic stirrer, condenser, and nitrogen inlet, $15 \mathrm{~g}(63.2 \mathrm{mmol}, 1$ equiv) of $\gamma$-benzyl L-glutamate and $8.13 \mathrm{~g}(27.4 \mathrm{mmol}, 0.43$ equiv) of triphosgene were added and purged with nitrogen for $10 \mathrm{~min}$. Freshly distilled ethyl acetate $(250 \mathrm{~mL})$ over $\mathrm{CaH}_{2}$ was added, and the mixture was brought to $145^{\circ} \mathrm{C}$. After several hours (4 to $5 \mathrm{~h}$ ), by checking the emission of $\mathrm{HCl}$ and total solution of the reacting mixture, the reaction was cooled down. The monomer was recrystallized from ethyl acetate/cyclohexane. Yield: $15.3 \mathrm{~g}$ $(91 \%) .{ }^{1} \mathrm{H}$ NMR $\left(360 \mathrm{MHz}\right.$, acetone- $\left.d_{6}, \delta\right): 7.98(1 \mathrm{H}, \mathrm{s}, \mathrm{NH})$, 7.26-7.43 (5H, m, Ar), $5.12\left(2 \mathrm{H}, \mathrm{s}, \mathrm{Ar}-\mathrm{CH}_{2}\right), 4.64(1 \mathrm{H}, \mathrm{t}$, $\alpha-\mathrm{CH}, J=6.5 \mathrm{~Hz}), 2.63\left(2 \mathrm{H}, \mathrm{t}, \gamma-\mathrm{CH}_{2}, J=7.7 \mathrm{~Hz}\right), 2.45(1 \mathrm{H}, \mathrm{m}$, $\beta$-CH), 2.14 (1H, m, $\beta$-CH). FTIR (ATR-diamond): 3256 (st, $\mathrm{N}-\mathrm{H}), 3066$ (st, ArC-H), 2936 (st, C-H), 1774 (st, C=O), 1703 (st, $\mathrm{NC}=\mathrm{O}), 1254(\mathrm{st}, \mathrm{C}-\mathrm{O}), 930(\delta, \mathrm{ArC}-\mathrm{C}), 740 \mathrm{~cm}^{-1}\left(\gamma, \mathrm{CH}_{2}\right)$.

Polymer Synthesis. For the polymerization process, ${ }^{37}$ the addition was modified to obtain narrow polymer distributions. ${ }^{38}$ The amino-terminated poly(propylene oxide) macroinitiator and the $\gamma$-benzyl L-glutamate $N$-carboxyanhydride (BLG-NCA) monomer were dissolved at room temperature in separated dried flasks in DMF and under a nitrogen atmosphere. The monomer solution was transferred via syringe to the polymer solution. The mixture was stirred at room temperature for three days under an inert nitrogen atmosphere. After polymerization, the solvent was evaporated at low pressure. The resulting concentrated polymer solution was dissolved in DCM and reprecipitated from methanol. After centrifugation and removal of the supernatant (three times), the resulting rubberlike material was freeze-dried for half a day. Yield: 80-90\%. ${ }^{1} \mathrm{H}$ NMR $\left(360 \mathrm{MHz}\right.$, acetone- $\left.d_{6}, \delta\right)$ : 7.80-8.80 $(\mathrm{NH}), 7.00-7.60(\mathrm{Ar}), 4.80-5.40\left(\mathrm{Ar}-\mathrm{CH}_{2}\right), 3.80-4.50(\alpha-\mathrm{CH})$, $3.20-3.80\left(\mathrm{CH}_{2} \mathrm{CH}\right), 1.80-3.00\left(\beta-\mathrm{CH}_{2}\right.$ and $\left.\gamma-\mathrm{CH}_{2}\right), 0.80-1.40$ $\left(\mathrm{CH}_{3}\right)$. FTIR (ATR-diamond): 3256 (st, N-H), 3066 (st, ArC-H), 2936 (st, C-H), 1774 (st, $\mathrm{C}=\mathrm{O}), 1703$ (st, $\mathrm{NC}=\mathrm{O}), 1254$ (st, C-O), $930\left(\delta\right.$, ArC-C), $740 \mathrm{~cm}^{-1}\left(\gamma, \mathrm{CH}_{2}\right)$.

Techniques. ${ }^{1} \mathrm{H}$ NMR and $2 \mathrm{D}{ }^{1} \mathrm{H}-{ }^{1} \mathrm{H}$ cosy-NMR measurements were carried out at room temperature on a Bruker DPX360 spectrometer operating at $360 \mathrm{MHz}$ and using $\mathrm{CDCl}_{3}$ or acetone- $d_{6}$ as solvents and as the internal standards. Gel permeation chromatography (GPC) analyses were performed at $35^{\circ} \mathrm{C}$ using a Viscotek GPC system equipped with a triple detector array (refractive index, light scattering, and viscosity). A PL-Gel mixed-C and a PL-gel mixed-D column set from Polymer Laboratories (pore size $5 \mu \mathrm{m}$ ) was connected in series in order of increasing pore size, using chloroform as an eluent at a flow rate of $1 \mathrm{~mL} / \mathrm{min}$. The molecular weight calibration curve was obtained using polystyrene standards. Differential scanning calorimetry (DSC) experiments were carried out on a PerkinElmer DSC Pyris 1 apparatus with heating and cooling rates of $10^{\circ} \mathrm{C} /$ min under a nitrogen atmosphere using $50 \mu \mathrm{L}$ aluminum pans with holes. A Leica DM LB optical microscope equipped with a Linkam CSS450 hot stage was used to analyze the anisotropic textures under cross polarizers. Fourier transform infrared (FTIR) spectra of solid samples were recorded at room temperature with a Bruker Tensor 27 FTIR spectrometer and using a MKII golden gate single attenuated total reflection
(ATR) system. FTIR spectra were analyzed by the second derivative technique for the determination of the peaks maxima, and followed by the deconvolution technique in a series of Lorentzian distributions to quantify the peaks population in the amide I region. Transmission electron microscopy (TEM) images were obtained by using a Philips TEM (CM 100) instrument operated at $80 \mathrm{kV}$. The samples were cryo-ultramicrotomed at $-80^{\circ} \mathrm{C}$ using a diamond knife on a Leica Ultracut UCT ultramicrotome to give $50 \mathrm{~nm}$ thick sections. Sections were then transferred onto 600-mesh carbon-coated copper grids. For a selective staining of the benzyl groups present on the PBLG block, the sections were exposed for 5 min to vapors of a freshly prepared aqueous $\mathrm{RuO}_{4}$ solution. Simultaneous small and wide-angle X-ray scattering (SWAXS) measurements were performed using an Anton-Paar SAXSess diffractometer with a fine line focus sealed copper tube (PANalytical, PW 3830) to obtain direct information on the high and low scattering vector ranges, respectively. $\mathrm{Cu} K \alpha$ radiation $(\lambda=1.54 \AA)$ was filtered by a Göbel mirror and a Kratky block collimation system. The scattered X-ray intensity was collected on a Packard Cyclone storage phosphor screen image plate $(200 \times 66 \mathrm{~mm}, 50 \times 50 \mu \mathrm{m} /$ pixel resolution) or by a Princeton Instruments CCD camera $(2084 \times 2084$ pixels, $24 \times 24 \mu \mathrm{m} /$ pixel $)$, depending on the scattering vector region of interest. Samples were placed in a self-constructed holder where temperature was controlled by a thermostat. Backgrounds from mica foils used to clamp the samples were subtracted from the diffractograms. An effective scattering-vector range of $0.08<q<28 \mathrm{~nm}^{-1}$ is obtained, where $q$ is the scattering wave-vector defined as $q=4 \pi \sin (\theta) / \lambda$, with a scattering angle of $2 \theta$.

\section{Results and Discussion}

One of the objectives of the present work was the study of the effects that systematic changes in the molecular architectures of block copolymers have in the final self-assembled solid-state structures; of particular interest was the disentanglement of the contribution from the specific secondary structure of the polypeptide from the other parameters controlling the self-assembly behavior. For these reasons, ten different block copolymers in a narrow composition range were synthesized by ring-opening polymerization (ROP) of the NCA monomer from $\gamma$-benzyl L-glutamate and analyzed in terms of their chemical composition, thermal behavior, secondary structure development, and supramolecular organization.

Synthesis and Characterization of the Block Copolymers. Two sets of volume fractions were selected for the block copolymers to allow long $(\phi=0.75)$ or shorter $(\phi=0.50)$ polypeptide blocks; these two different conditions are expected to promote either rodlike $\alpha$-helical secondary structures or coexistence of the former with $\beta$-sheets, respectively. In Scheme 1, the chemical structures of the amino-terminated macroinitiators as well as the final structures of all synthesized ten block copolymers are shown.

The reaction was carried out by the addition of the NCA monomer to the macroinitiator in DMF and purified by reprecipitation of DCM solutions of the polymers in cold methanol. To evaluate the chemical composition and the number of repeating units of the peptide segment into the different block copolymers, their ${ }^{1} \mathrm{H}$ NMR spectra were carefully analyzed. In this way, the integration of the signals from the five aromatic protons ( 7.00 to $7.60 \mathrm{ppm})$, the two benzylic protons (4.80 to $5.40 \mathrm{ppm}$ ), or the proton in the $\alpha$ position (3.80 to $4.50 \mathrm{ppm}$ ) with respect to the three protons related to the methyl group of the propylene oxide unit $(0.80$ to $1.40 \mathrm{ppm})$ were used to calculate the number of $\gamma$-benzyl L-glutamate units as well as to obtain an estimation of the number-average molecular mass of the peptide block. In Table 1, the results from these evaluations are shown 
Scheme 1. Chemical Structure of the NCA Monomer (BLG-NCA), the Five Amino-Terminated Macroinitiators, and the Ten Rod-Coil Block Copolymers As a Function of the Volume Fraction of the Polypeptide Segment

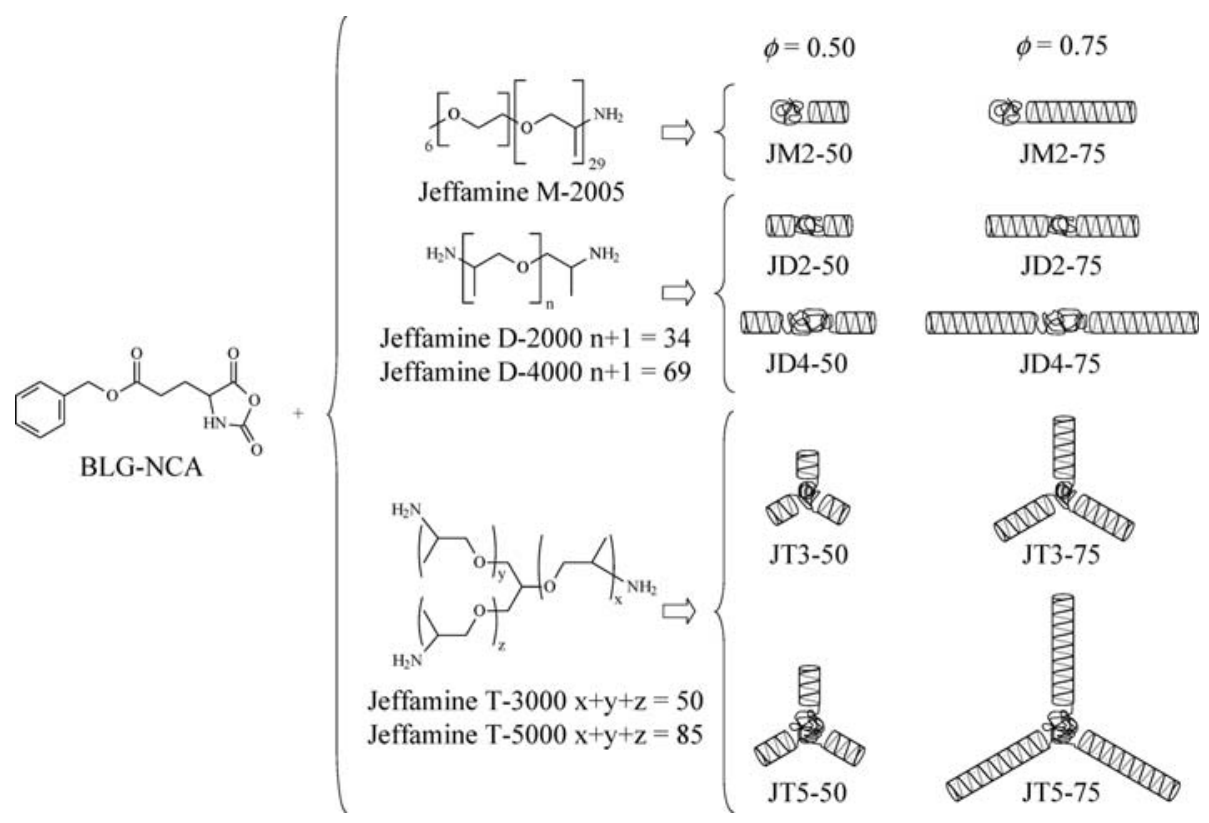

Table 1. Degree of Polymerization of the Polypeptide Block (DP $\left.\mathrm{PBLG}_{\mathrm{G}}\right)$, Degree of Polymerization of the Arms $\left(\mathrm{DP}_{\mathrm{arm}}\right)$, Number Average Molecular Masses of the Macroinitiators $\left(M_{\mathrm{n}, \mathrm{PPO}}\right)$, the Polypeptide $\left(\boldsymbol{M}_{\mathrm{n}, \mathrm{PBLG}}\right)$, and the Block Copolymer $\left(\boldsymbol{M}_{\mathrm{n}}\right)$ by ${ }^{1} \mathrm{H}$ NMR, Volume Fraction of the Polypeptide Block $(\phi)$, and Their Corresponding Calculated End-to-End Distances for Rodlike $\alpha$-Helix Structure $\left(l_{\alpha}\right)$ or Stretched Chain $\beta$-Sheet $\left(l_{\beta}\right)$

\begin{tabular}{|c|c|c|c|c|c|c|c|c|}
\hline samples & $\mathrm{DP}_{\mathrm{PBLG}}$ & $\mathrm{DP}_{\text {arm }}$ & $M_{\mathrm{n}, \mathrm{PPO}}(\mathrm{Da})$ & $M_{\mathrm{n}, \mathrm{PBLG}}(\mathrm{Da})$ & $M_{\mathrm{n}}(\mathrm{Da})$ & $\phi^{a}$ & $l_{\alpha}(\mathrm{nm})$ & $l_{\beta}(\mathrm{nm})$ \\
\hline JM2-50 & 12 & 12 & 2000 & 2600 & 4600 & 0.51 & 1.8 & 4.2 \\
\hline JD2-50 & 13 & 7 & 2000 & 2900 & 4900 & 0.53 & 1.0 & 2.3 \\
\hline JD4-50 & 24 & 12 & 4000 & 5300 & 9400 & 0.51 & 1.8 & 4.2 \\
\hline JT3-50 & 18 & 6 & 3000 & 3900 & 6900 & 0.50 & 0.9 & 2.1 \\
\hline JT5-50 & 31 & 10 & 5000 & 6900 & 11900 & 0.52 & 1.6 & 3.7 \\
\hline JM2-75 & 33 & 33 & 2000 & 7200 & 9200 & 0.74 & 4.9 & 11.4 \\
\hline JD2-75 & 37 & 19 & 2000 & 8200 & 10200 & 0.76 & 2.8 & 6.5 \\
\hline JD4-75 & 66 & 33 & 4000 & 14500 & 18500 & 0.74 & 5.0 & 11.6 \\
\hline JT3-75 & 55 & 18 & 3000 & 12000 & 15000 & 0.76 & 2.7 & 6.3 \\
\hline JT5-75 & 91 & 30 & 5000 & 20000 & 25000 & 0.76 & 4.6 & 10.7 \\
\hline
\end{tabular}

together with the theoretical end-to-end distance of the rodlike peptide block. The latter was calculated considering that the $\alpha$-helix has a pitch of $0.54 \mathrm{~nm}$ per 3.6 amino acid residues, whereas the $\beta$-sheets strandlike peptide block is fully extended with $0.35 \mathrm{~nm}$ length increase per amino acid. Both secondary structures were assumed to occur without intra molecular folding.

From the values in Table 1 , it can be observed that the samples with high volume fraction $(\phi \approx 0.75)$ show an arm's degree of polymerization of approximately $\mathrm{DP}_{\mathrm{arm}} \geq 20$ that is expected to lead to $\alpha$-helical structures, as reported in literature. ${ }^{39}$ For the other volume fraction $(\phi=0.50)$ with arm's degree of polymerization $\mathrm{DP}_{\text {arm }}<20$, one should expect coexistence of $\alpha$-helices and $\beta$-sheets. To assess this point further in the present work, the degrees of polymerization reported in the Table were additionally investigated by GPC measurements (Supporting Information), and the results concerning their weight average $\left(M_{\mathrm{w}}\right)$ and number average $\left(M_{\mathrm{n}}\right)$ molecular masses and polydispersity indexes (PDI) are shown in Table 2. As can be observed in Table 2, GPC leads to systematic overestimation of the molecular weights, most likely as a consequence of the PS calibration standards used that cannot perfectly capture the extended chain configurations expected for the PBLG blocks. This is, however, expected to have very little influence on the evaluation of PDI values for each individual block copolymer. The observed increase in the polydispersity is a function of the architecture of the macroinitiator and is due to the statistical accumulation of the peptide distributions on the final polymer (di-, tri-, or tetrablock copolymers).

The thermal behavior of all block copolymers was analyzed by DSC to check whether the systems present transition temperatures that can be correlated with glass transition $\left(T_{\mathrm{g}}\right)$ or order-disorder $\left(T_{\mathrm{ODT}}\right)$ or order-order $\left(T_{\mathrm{OOT}}\right)$ transitions, corresponding to temperature-assisted reorganization of the peptide blocks into the block copolymer melts. In Figure 1 typical DSC curves of two block copolymers obtained from the same macroinitiator are compared. The sample with higher peptide volume fraction $(\phi=0.75)$ presents an endothermic, sharper peak at a higher temperature than the corresponding system with lower volume fraction $(\phi=0.50)$ as well as larger enthalpy underneath the peak. This effect can be explained by the higher temperatures and energies needed to allow molecular readjustment of long segments of the block peptide, as can be observed from the enthalpy under the peaks. 
Table 2. Number Average Molecular Mass $\left(M_{\mathrm{n}}\right)$, Weight Average Molecular Mass $\left(M_{\mathrm{w}}\right)$, and Polydispersity Indexes $\left(\operatorname{PDI}=M_{\mathrm{w}} / M_{\mathrm{n}}\right)$ for the Ten Block Copolymers

\begin{tabular}{|c|c|c|c|c|c|}
\hline samples & $M_{\mathrm{n}}(\mathrm{calcd})(\mathrm{Da})^{a}$ & $M_{\mathrm{n}}(\mathrm{NMR})(\mathrm{Da})$ & $M_{\mathrm{n}}(\mathrm{GPC})(\mathrm{Da})$ & $M_{\mathrm{w}}(\mathrm{GPC})(\mathrm{Da})$ & PDI \\
\hline JM2-50 & $4600(12)$ & $4600(12)$ & $7600(34)$ & 10900 & 1.44 \\
\hline JD2-50 & $4600(6)$ & $4900(7)$ & 6300 (14) & 9200 & 1.45 \\
\hline JD4-50 & $9300(12)$ & 9400 (12) & $1100(26)$ & 19700 & 1.72 \\
\hline JT3-50 & $6900(6)$ & $6900(6)$ & $10200(16)$ & 18800 & 1.84 \\
\hline JT5-50 & $11600(10)$ & $11900(10)$ & $15600(24)$ & 28600 & 1.84 \\
\hline JM2-75 & $9400(34)$ & $9200(33)$ & $13900(64)$ & 20500 & 1.47 \\
\hline JD2-75 & 9700 (18) & 10200 (19) & $10700(24)$ & 16600 & 1.55 \\
\hline JD4-75 & $19200(35)$ & $18500(33)$ & $18100(41)$ & 25600 & 1.41 \\
\hline JT3-75 & $14200(17)$ & $15000(18)$ & $19300(29)$ & 32800 & 1.70 \\
\hline JT5-75 & $23900(29)$ & $25000(30)$ & $30100(46)$ & 52400 & 1.74 \\
\hline
\end{tabular}

${ }^{a}$ In parentheses the estimated number of repeating units in the arms.

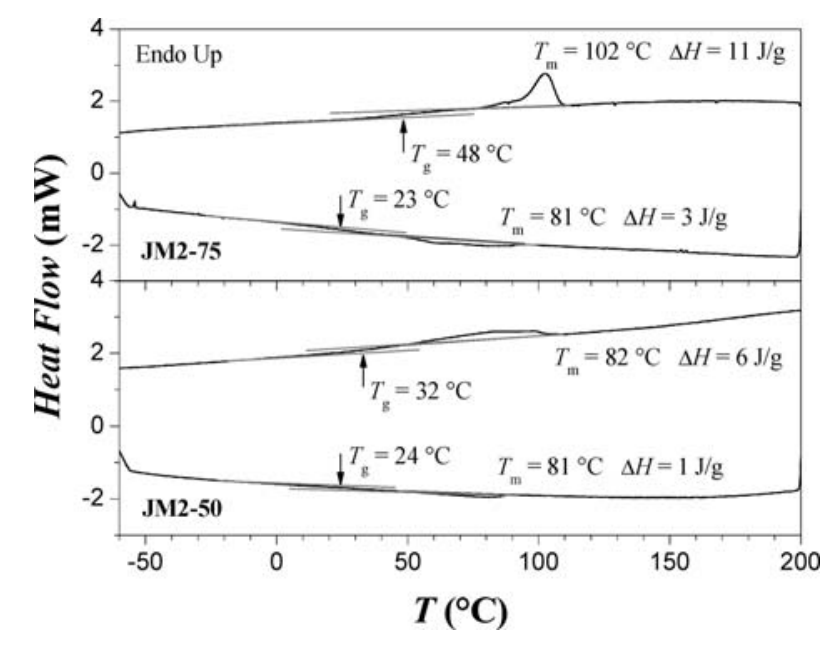

Figure 1. DSC curves of two samples (JM2-75 and JM2-50), showing different thermal behavior as a result of different polypeptide block lengths.

Another interesting effect is observed on the glass transition temperature of the samples, where only one $T_{\mathrm{g}}$ is observed (corresponding to the PBLG block), which is increasing with peptide volume fraction/length content: this is consistent with expectations for a PBLG block of increasing molecular weight that is microphase separated from the PPO block.

In general, samples with a high number of repeating amino acid units (JM2-75, JD4-75, and JT5-75) show endothermic peaks around $T_{\mathrm{m}}=105^{\circ} \mathrm{C}$, whereas samples with a medium degree of polymerization of the peptide arms (JM2-50, JD450, JT5-50, JD2-75, and JT3-75) show lower transition temperatures around $T_{\mathrm{m}}=85$ to $95^{\circ} \mathrm{C}$. Special mention should be given to the samples with the lowest degree of polymerization (JD2-50 and JT3-50) that present the lowest clearing temperatures at $T_{\mathrm{m}}=77^{\circ} \mathrm{C}$. In Table 3, the glass transition temperatures, endothermic peaks, and enthalpies are given for all block copolymers investigated. It appears that the degree of polymerization and the temperatures of the peaks are correlated to some extent, which can be explained by the energetic cost to allow mobility of the peptide chains. This argument and the exact physical attribution of $T_{\mathrm{m}}$ to an order-to-disorder transition (liquid-crystalline-to-isotropic) will be discussed in more detail in the next sections and reinforced by X-ray temperature-dependent experiments.

Secondary Structure of the Peptide Block. In what is discussed above, we have analyzed the chemical composition and the thermal behavior of all block copolymer systems. We do want to address now the issue of whether the secondary structure of the polypeptide block can affect the
Table 3. Glass Transition Temperatures $\left(T_{\mathrm{g}}\right)$, Endothermic Peaks $\left(T_{\mathrm{m}}\right)$, and Enthalpies $(\Delta H)$ from the DSC Curves of the Ten Samples Studied

\begin{tabular}{lccc}
\hline samples & $T_{\mathrm{g}}\left({ }^{\circ} \mathrm{C}\right)$ & $T_{\mathrm{m}}\left({ }^{\circ} \mathrm{C}\right)$ & $\Delta H(\mathrm{~J} / \mathrm{g})$ \\
\hline JM2-50 & 32 & 82 & 5.9 \\
JD2-50 & 35 & 77 & 5.7 \\
JD4-50 & 40 & 94 & 5.5 \\
JT3-50 & 34 & 77 & 4.7 \\
JT5-50 & 52 & 82 & 1.3 \\
JM2-75 & 48 & 102 & 11 \\
JD2-75 & 26 & 94 & 8.2 \\
JD4-75 & 30 & 106 & 7.8 \\
JT3-75 & 41 & 84 & 11 \\
JT5-75 & 47 & 105 &
\end{tabular}

self-organization of the block copolymers and to what extent this is possible. It is well-known that homopolypeptides based on $\gamma$-benzyl L-glutamate organize into $\alpha$-helices (3.6 residues with $0.54 \mathrm{~nm}$ pitch) for long degrees of polymerization or a mixture of them with $\beta$-sheets (two residues with $0.70 \mathrm{~nm}$ distance) for short ones. ${ }^{40}$ The presence of these architectures is therefore also expected to have an impact on the supramolecular structure of the systems.

The secondary structure of the peptide block was analyzed in the present work by FTIR. The polypeptides, being polyamides, have a strong absorption band in the amide I (1620 to $1690 \mathrm{~cm}^{-1}$ ) region, ${ }^{41}$ which corresponds to the vibrational mode from the $\mathrm{C}=\mathrm{O}$ stretching of the amide group coupled to the $\mathrm{N}-\mathrm{H}$ bending and the $\mathrm{C}-\mathrm{N}$ stretching as well as to the presence of hydrogen bonding. Carefully analyzed FTIR spectra enable the quantification of the $\alpha$-helix $\left(1650-1660 \mathrm{~cm}^{-1}\right),{ }^{42} \beta$-sheet $(1620-1640$ and $1670-$ $\left.1680 \mathrm{~cm}^{-1}\right),{ }^{43}$ and random coil or turn populations (1640$1650,1660-1670$, and $\left.1680-1690 \mathrm{~cm}^{-1}\right) .{ }^{44}$ The amide I region was first analyzed by the second derivative technique $^{45,46}$ that allows the qualitative determination of the peaks maxima of each contribution. The second step was the deconvolution technique ${ }^{47}$ in a series of Lorentzian distributions to quantify the population of each of the peaks. ${ }^{48}$ In the Supporting Information, two examples are given where the sample with high volume fraction (JD4-75) shows almost exclusively $\alpha$-helices, and the sample with lower volume fraction (JD2-50) shows a mixture of $\alpha$-helices and $\beta$-sheets.

To understand the process taking place upon heating the samples, all systems were analyzed before and after thermal treatment at $200{ }^{\circ} \mathrm{C}$ ( 5 min under $\mathrm{N}_{2}$ atmosphere). In Figure 2, the contribution to the amide I region for all samples before and after annealing is given. From these results, two tendencies can be observed. First, the samples with volume fractions of $\phi=0.50$ generally have a lower $\alpha$-helix content and higher $\beta$-sheet or unordered segments with respect to their homologues of volume fractions of $\phi=0.75$ because of the increase in repeating units in the PBLG block that stabilizes the 


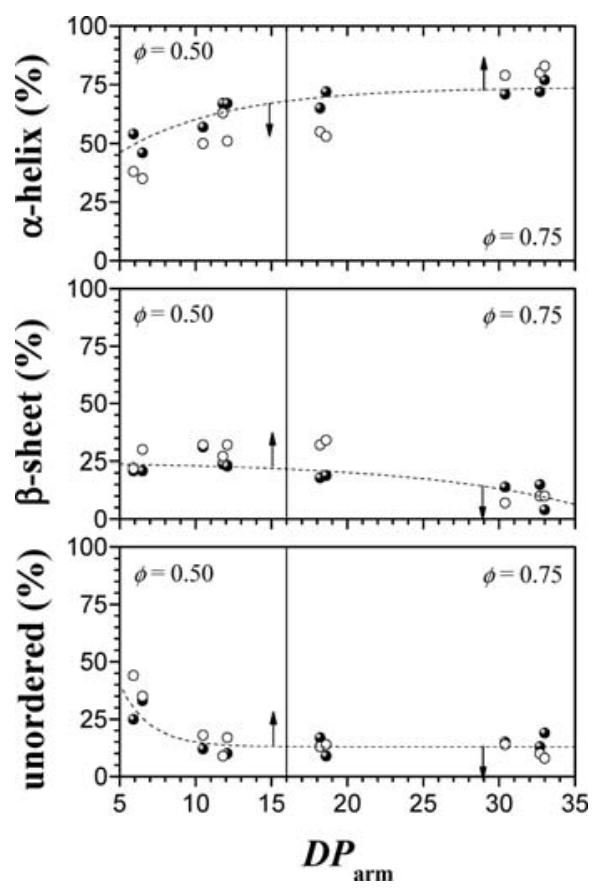

Figure 2. FTIR secondary structure populations ( $\alpha$-helix, $\beta$-sheet, and unordered) of the samples before $(-)$ and after annealing at $200{ }^{\circ} \mathrm{C}(\mathrm{O})$. (The arrows indicate the tendency after annealing, and the lines are a help to eyes only).

helical rod. Second, for the low peptide content systems $(\phi=$ 0.50 ), the $\alpha$-helix population decreases after annealing because of the increase in both the $\beta$-sheet and unordered populations. This is presumably related to the insufficient amount of intramolecular hydrogen bonds needed to maintain the helix stable at high temperatures. It should be emphasized that those samples that showed the endothermic peak around $T_{\mathrm{m}}=105^{\circ} \mathrm{C}$ are an exception with respect to the rest of block copolymers because they showed an increase in the rod percentage population after annealing. This can be explained by a cooperative effect where the preexisting $\alpha$-helices help to stabilize the final secondary structure by increasing the length of the resulting $\alpha$-helical rods. This effect can be easily observed for the sample JD4-75 (increase of rods), together with the opposite for the sample JD2-50 (increase in strands). (See the Supporting Information.)

Solid-State Organization of the Block Copolymers. At the volume fractions considered in the present study, only lamellar structures should be expected; to characterize solidstate structures for the various block copolymer systems, $\mathrm{X}$-ray measurements were performed at different temperatures together with TEM.

As described above, the number of repeating units in the arms of the polypeptide block is of great importance in defining the secondary structure, and it is ultimately also important for the self-assembly features of the block copolymers. ${ }^{18,49}$ Considering the degree of polymerization in the polypeptide arms, three classes of samples can be identified showing a similar behavior within each individual class: (i) $\mathrm{DP}_{\text {arm }}<10$ (JD2-50 and JT3-50), (ii) $10<\mathrm{DP}_{\text {arm }}<20$ (JM2-50, JD4-50, JT5-50, JD2-75, and JT3-75), and DP ${ }_{\text {arm }}>$ 20 (JM2-75, JD4-75, and JT5-75). The analysis of the X-ray diffractograms of the samples at $25{ }^{\circ} \mathrm{C}$, before and after annealing at $200^{\circ} \mathrm{C}$, shown in Figure 3 for three representative samples, can be summarized in what follows.

(i). Low q Range. All samples do show some signs of microphase segregation between the polypeptide block and the polymer melt, as indicated from the peaks at low $q$ values,
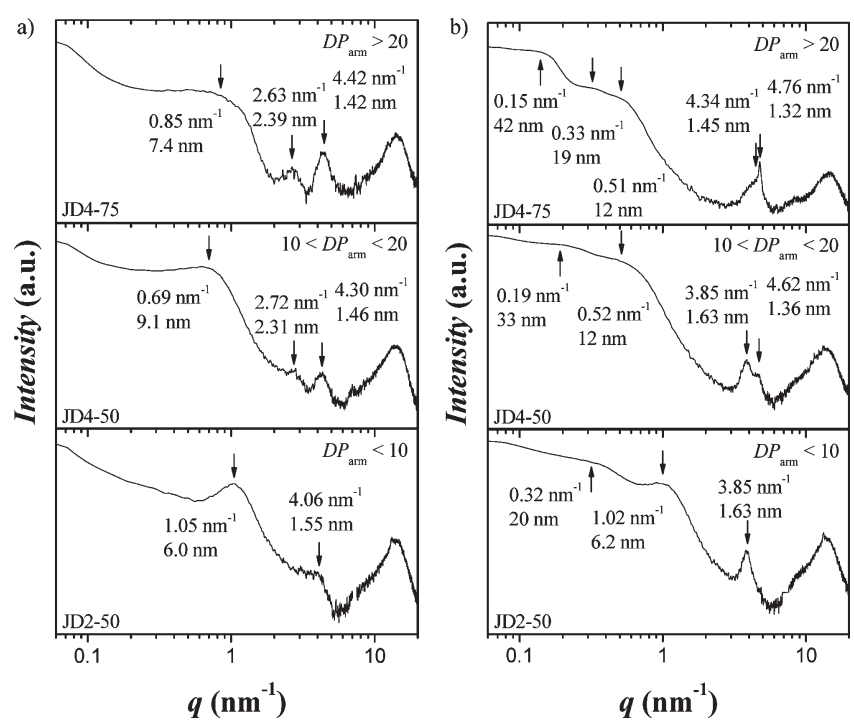

Figure 3. SWAXS diffractograms for the samples JD4-75, JD4-50, and JD2-50 (a) at $25^{\circ} \mathrm{C}$ and (b) at $25^{\circ} \mathrm{C}$ after annealing at $200{ }^{\circ} \mathrm{C}$.

although peaks remain extremely broad in each case. Before annealing, these $q$ values are in the range $0.70(9 \mathrm{~nm})<q<$ $1.10 \mathrm{~nm}^{-1}(6 \mathrm{~nm})$, whereas upon annealing, they move to lower $q$ ranges: $0.50(13 \mathrm{~nm})<q<1.00 \mathrm{~nm}^{-1}(6 \mathrm{~nm})$. Furthermore, upon annealing, in particular, the samples with high molecular weight, exhibit additional broad reflections in the regions $q<0.30 \mathrm{~nm}^{-1}$, indicating features $>20 \mathrm{~nm}$ in real space. The surprising indication is that despite the expected lamellar packing, in general, the peaks do not correlate with the multiple order Bragg reflections typical of a well-organized lamellar phase.

In a lamellar packing of rod-coil block copolymers, two different packing mechanisms can be expected: a smectic A type, in which the rods are perfectly orthogonal to the lamellae interfaces and a smectic $\mathrm{C}$, in which the rods are tilted. For the model of the perpendicular polypeptide distribution in the lamella (smectic A), we consider the volume fraction of the polymer melt, its radius of gyration, and the secondary structure of the polypeptide block ( $\alpha$-helices, $\beta$-sheets, and unordered segments) and its degree of polymerization in one arm to determine the number of polypeptide segments perpendicular into the layer. Because the low $q$ peaks appear to be uncorrelated for most of the samples, we analyze the results with respect to the low $q$ reflections in the two different ranges $0.10<q<0.30$ and $0.30<q<1.00 \mathrm{~nm}^{-1}$. The results show that in the smaller real space length scale region $\left(0.30<q<1.00 \mathrm{~nm}^{-1}\right)$, for the low volume fraction samples $(\phi=0.50)$, two polypeptide blocks can fit into one layer, whereas for the high volume fraction samples $(\phi=$ $0.75)$, only one rod fits in a monolayer, ${ }^{23}$ or two tilted rods in a smectic $\mathrm{C}$ configuration also fit.

However, if the $q$ range $0.10<q<0.30 \mathrm{~nm}^{-1}$ is considered, then no possible lamellar packing mechanisms can be rationalized using the average molecular weights measured and reported in Tables 2 and 3 . The only possible explanation, which will be supported and elucidated below, is that only the highest molecular weight fractions of the block copolymers can be responsible for these low $q$ features.

(ii). High q Range. The peaks in the region between $2.63<$ $q<4.76 \mathrm{~nm}^{-1}$ are characteristic of the organization in the solid state of the secondary structures of the polypeptide blocks. Before annealing, the peaks in this region are broad and typically split into two peaks at around $q \approx 4.1$ to $4.4 \mathrm{~nm}^{-1}$ (1.4 to $1.5 \mathrm{~nm}$ ) and 2.6 to $2.7 \mathrm{~nm}^{-1}$ (2.3 to $2.4 \mathrm{~nm}$ ), which 
corresponds neither to the well-known packing of $\alpha$-helices $\left(q_{\alpha} \approx 4.65 \mathrm{~nm}^{-1} ; d_{\alpha}=1.35 \mathrm{~nm}\right)$ nor to the strands of $\beta$-sheets $\left(q_{\beta} \approx 3.52 \mathrm{~nm}^{-1} ; d_{\beta}=1.78 \mathrm{~nm}\right)$. We propose that in this region, something in between the two precise secondary structures takes place: a mixture of $\alpha$ - and $\beta$-interaction arrays (the disturbed helices packing). After annealing (Figure $3 b$ ), both peaks move toward those of pure helical hexagonal packing and $\beta$-sheets, indicating an improved order on these length scales. For molecular weight large enough, the exact packing of helical hexagonal packing is found $\left(\mathrm{DP}_{\mathrm{arm}}>20\right.$ and $\left.10<\mathrm{DP}_{\mathrm{arm}}<20\right)$, whereas for $\mathrm{DP}_{\mathrm{arm}}<$ 10 , a single peak appears around $q \approx 3.85 \mathrm{~nm}^{-1}(1.6 \mathrm{~nm})$, revealing that both $\alpha$-helices and $\beta$-sheets coexist. These results are in very good agreement with the analysis based on FTIR presented above.

(iii). Samples with $D P_{\text {arm }}>$ 20. Samples JM2-75, JD4-75, and JT5-75 are the only ones to exhibit a perfectly sharp peak at $q \approx 4.7 \mathrm{~nm}^{-1}(1.33 \mathrm{~nm})$ that is a nicely packing of $\alpha$-helical rods. In addition, these samples are the ones that show the most evident additional low $q$ reflections $(q \approx 0.15$ and $0.30 \mathrm{~nm}^{-1}$ ) appearing after annealing and which are presumably the indication of lamellar structure arising from high molecular weight fractions of the block copolymers. Calculations based on this hypothesis reveal possible packing of two perpendicular rods (smectic A) of high molecular weight in the lamellar layers. The JD4-75 SAXS profile for examples (Figure 3b, top), shows what could be two $q_{1} / q_{2}$
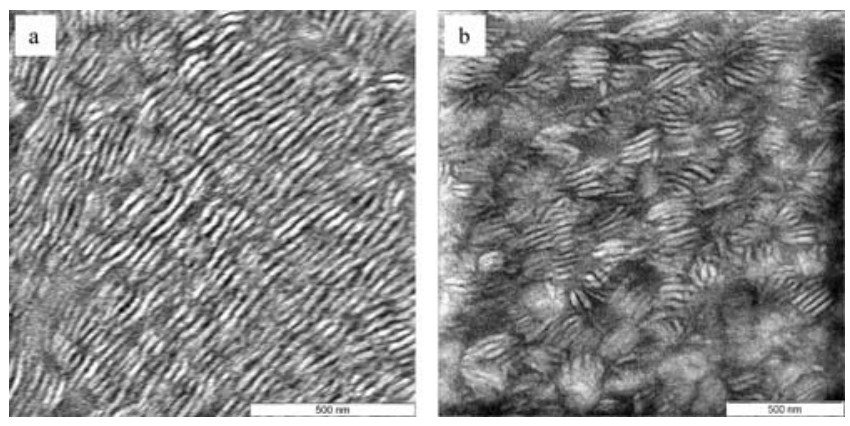

Figure 4. TEM images from the sample JD4-75 after annealing at $200{ }^{\circ} \mathrm{C}$. (a) Well-ordered domains and (b) clusters showing the phase separation between high $\alpha$-helix content (lamellar zones) and mixture of secondary structures (gray zones). The system shows no ordered microphase separation before annealing. correlated reflections at $0.15: 0.33 \mathrm{~nm}^{-1}$ corresponding to 40:20 nm, plus an additional uncorrelated reflection at $0.51 \mathrm{~nm}^{-1}(12 \mathrm{~nm})$. Given the broadness of the peaks, however, any conclusive rationalization of these results can be achieved only via complementary experimental techniques.

To do so, additional TEM experiments were carried out on all samples. No precise microphase separation could be identified by TEM in the samples with lower molecular weights, confirming the low to no order expected on the basis of SAXS analysis. However, samples JM2-75, JD4-75, and JT5-75 did show clear evidence of structure formation on the block copolymer length scale.

For these samples, the results (see Figure 4 for an example) indeed support a macrophase separation between ordered lamellar regions (with period $\approx 35 \mathrm{~nm}$ ) and regions where lamellar clusters coexist with disordered isotropic-like dark regions. Taken together with the monomodal distribution of the corresponding block copolymers in the GPC curves, the FTIR analysis and the SAXS data, these results are perfectly consistent with a macrophase separation induced by the partitioning of secondary structures: in this picture, high molecular weight components of the system with a high amount of $\alpha$-helical rods (the lamellar regions) would phase separate from lower molecular weight components exhibiting a mixture of $\alpha$-helical, $\beta$-sheets, and coils (the disordered isotropic-like regions).

Finally, to reinforce and ultimately demonstrate this selfassembly scheme, polarized optical microscopy under shearing was carried out (Figure 5). All samples except the three with high peptide degree of polymerization (JM2-75, JD475, and JT5-75) revealed what was previously observed. They are birefringent below their clearing temperature $\left(T_{\mathrm{m}}\right)$, and they are isotropic and flow above, showing that this endothermic transition is an order-disorder transition (liquid-crystalline-to-isotropic).

The other three samples mentioned above with $\mathrm{DP}_{\mathrm{arm}}>$ 20 show the same feature below the endothermic peak; however, above $T_{\mathrm{m}}$, they are still birefringent. Surprisingly, macroscopic phase separation could be observed, where some anisotropic birefringent domains are randomly distributed within the isotropic viscous liquid (Figure 5b).

Temperature-dependent SAXS experiments on the samples JM2-75, JD4-75, and JT5-5 show the formation of the lamellar phase upon heating. As an example, in Figure 6, a set of SAXS measurements on the sample JM2-75 is shown.

a)

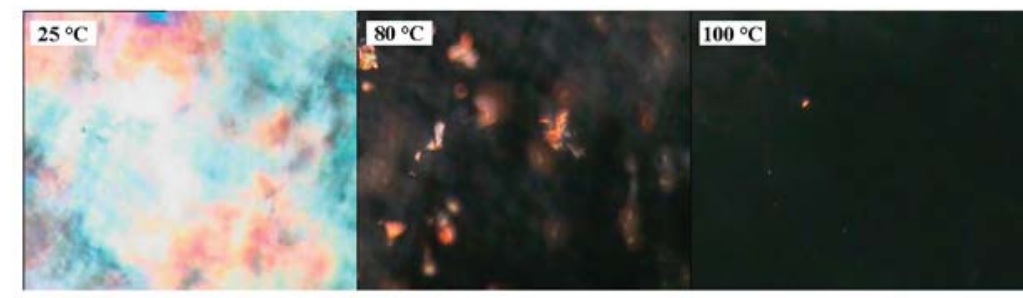

b)

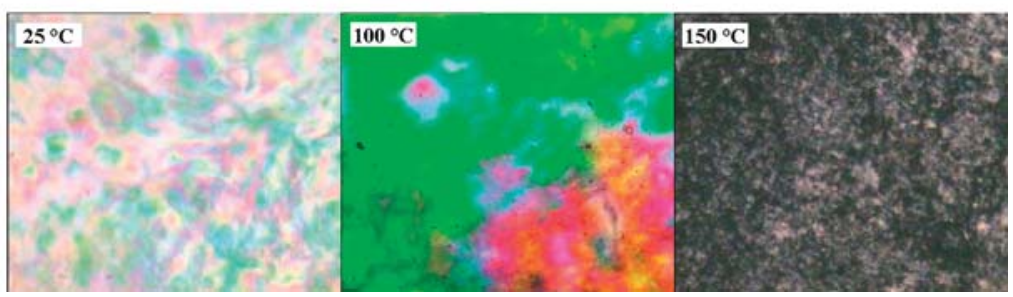

Figure 5. POM images of the samples (a) JD2-50 at 25, 80, and $100{ }^{\circ} \mathrm{C}$ and (b) JD4-75 at 25, 100, and $150{ }^{\circ} \mathrm{C}$. 


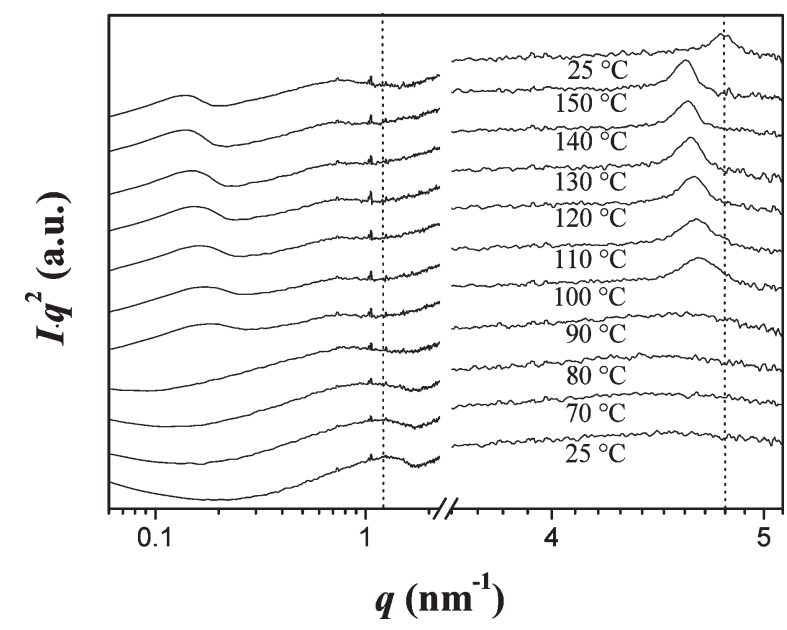

Figure 6. SAXS diffractograms as function of temperature for the sample JM2-75.
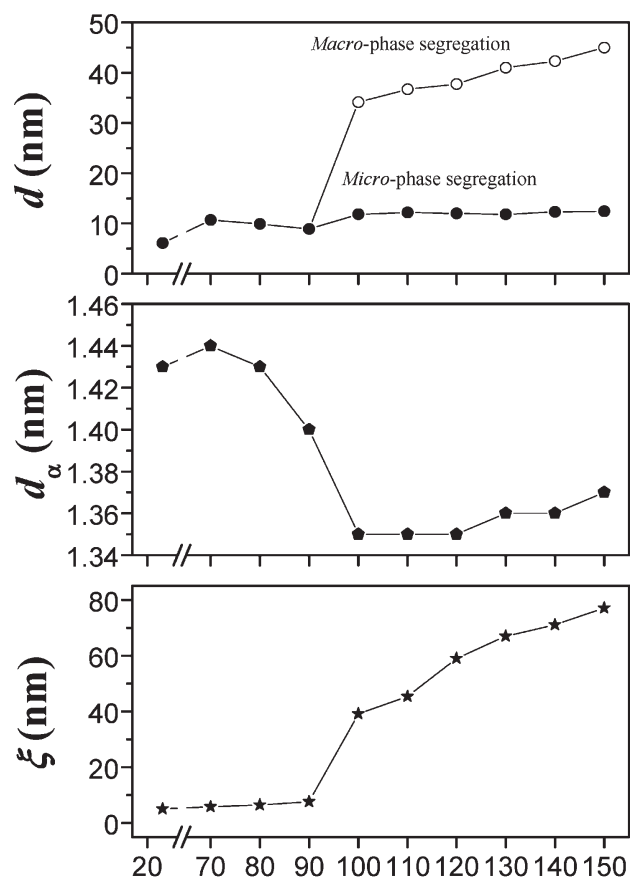

$\boldsymbol{T}\left({ }^{\circ} \mathrm{C}\right)$

Figure 7. Lamellar microphase segregation distance $(d), \alpha$-helical packing distance $\left(d_{\alpha}\right)$, and correlation length $(\xi)$ as function of temperature for the sample JM2-75.

It can be observed how, when going from 25 to $150^{\circ} \mathrm{C}$, a peak around $q \approx 4.65 \mathrm{~nm}^{-1}$ appears when the sample reaches $100{ }^{\circ} \mathrm{C}$. From here on, by increasing the temperature, the peak is getting narrower and shifts to lower $q$ values, which is expected on the basis of dilatation of the cross section and the expansion of the $\alpha$-helices interdistance. The formation of the helical packed structure occurs simultaneously with the formation of the lamellar phase, and this effect is observable by the appearance of the peak at $q \approx 0.14$ to $0.18 \mathrm{~nm}^{-1}$. This is consistent with the TEM analysis, which shows evidence of microphase separation for these systems only after annealing. Furthermore, this clearly shows that the microphase and macrophase separation is assisted by the formation of the $\alpha$-helical secondary structure.

Analyzing in more detail the SAXS diffractograms in Figure 6 and plotting the results as a function of temperature
(Figure 7), a clear tendency can be observed. First, the period of the lamellar phase $(d)$, the $\alpha$-helical distance between rods $\left(d_{\alpha}\right)$, and the correlation length between the macromolecular mesogens $(\xi)$, for example, the persistence length of the cross sectional lamellar phase, are increasing as a function of temperature. Second, in all three of these parameters, there is a clear discontinuity in the region between 90 to $100{ }^{\circ} \mathrm{C}$, already observed in the DSC thermograms. This once more supports and reinforces the arguments presented above: the high molecular weight fractions of the block copolymer distribution reorganize their secondary structure in a nearly pure $\alpha$-helix population, phase separate from the lower tail of the weight molecular distribution, and give rise to the formation of a long-period lamellar phase. Polydispersity in rod-coil block copolymers has been shown to produce features such as the undulation of lamellar phases ${ }^{50}$ but never a macrophase partitioning, as in the present case.

Finally, calculations based on the samples with high $\alpha$-helix content show that the interrod distance of these polypeptide rods is around 1.55 to $1.60 \mathrm{~nm}$, which fits well with the hexagonal packing of the helices with $q_{\alpha} \approx 4.65 \mathrm{~nm}^{-1}$ and $d_{\alpha}=1.35 \mathrm{~nm}$. Therefore, a distorted liquid-crystalline hexagonal distribution of high molecular weight polypeptide rods into a lamellar phase can be achieved upon heating samples with $>20$ repeating units in the PBLG segment.

\section{Conclusions}

Ten different polypeptide-based rod-coil block copolymers have been synthesized by ROP of the BLG-NCA monomers using amino-terminated macroinitiators based on polypropylene oxide. The number of rods attached to the polymer melt, the volume fraction of the rod polypeptidic block, and the degree of polymerization were varied systematically so that two main physical behaviors could be identified for these block copolymers, depending essentially on the number of repeating units present in the polypeptide block.

For samples with degree of polymerization in the arms $\mathrm{DP}_{\text {arm }}$ of less than 20, a mixture of secondary structures ( $\alpha$-helices, $\beta$-sheets, and unordered segments) is present along the polypeptide blocks, and the amount of $\alpha$-helical secondary structure is found to be directly proportional to the degree of polymerization. This mixture of secondary structures leads to a poorly ordered yet liquid-crystalline microphase separated solid state structure, as revealed by SAXS, TEM, POM, and DSC experiments.

For samples with a number of repeating units in the polypeptide block with $\mathrm{DP}_{\text {arm }}>20$, almost only $\alpha$-helical structure is observed, and microphase separation also occurs in these systems. The most important feature of this class of block copolymers, however, is that upon heating, the fraction with the highest polymerization degrees in the molecular weight distribution, (constituted by only $\alpha$-helices in their secondary structures) segregates from the lower molecular weights fractions, leading to a macrophase separation of high molecular weight lamellar phases coexisting with lower molecular weight poorly ordered clusters. In the poorly ordered clusters, a coexistence of $\alpha$-helices, $\beta$-sheets, and unordered segments is found, whereas in the lamellar phase, the periodicity is consistent with a bilayer of high molecular weight $\alpha$-helical rods in a smectic A configuration.

The key point that controls the formation of the lamellar phase in these systems is the degree of polymerization of the polypeptide blocks. Samples with more that 20 amino acid residues lead to a lamellar phase, in which helical rods contained in the peptide-rich layers are closely and nicely packed into a hexagonal lattice. If the polydispersity is not narrow enough, however, a secondarystructure-assisted macrophase separation takes place. 
Acknowledgment. We acknowledge financial support from the Swiss National Science Foundation. We gratefully acknowledge Dr. Thomas Schweizer at ETHZ for assistance with GPC measurements and wish to thank Prof. Dr. Harm-Anton Klok at EPFL for useful discussions.

\section{References and Notes}

(1) Reenders, M.; ten Brinke, G. Macromolecules 2002, 35, 3266-3280.

(2) Halperin, A. Macromolecules 1990, 23, 2724-2731.

(3) Matsen, M. W.; Barret, C. J. Chem. Phys. 1998, 109, 4108-4118.

(4) Pryamitsyn, V.; Ganesan, V. J. Chem. Phys. 2004, 120, 5824-2538.

(5) Chen, J. T.; Thomas, E. L.; Ober, C. K.; Hwang, S. S. Macromolecules 1995, 28, 1688-1697.

(6) Lee, M.; Cho, B. K.; Kang, Y. S.; Zin, W. C. Macromolecules 1999, 32, 7688-7691.

(7) Olsen, B. D.; Segalman, R. A. Macromolecules 2005, 38, 1012710137.

(8) Sary, N.; Rubatat, L.; Brochon, C.; Hadziioannou, G.; Ruokolainen, J.; Mezzenga, R. Macromolecules 2007, 40, 6990-6997.

(9) Sary, N.; Brochon, C.; Hadziioannou, G.; Mezzenga, R. Eur. Phys. J. E 2007, 24, 379-384.

(10) Zhong, X. F.; François, B. Macromol. Rapid Commun. 1988, 9, 411-416.

(11) François, B.; Pitois, O.; François, J. Adv. Mater. 1995, 7, 1041-1044.

(12) Marsitzky, D.; Klapper, M.; Müllen, K. Macromolecules 1999, 32, 8685-8688

(13) Leclère, P.; Calderone, A.; Marsitzky, D.; Francke, V.; Geerts, Y.; Müllen, K.; Brédas, J. L.; Lazzaroni, R. Adv. Mater. 2000, 12, 1042-1046.

(14) Li, W.; Wang, H.; Yu, L.; Morkved, T. L.; Jaeger, H. M. Macromolecules 1999, 32, 3034-3044.

(15) Zhang, G.; Fournier, M. J.; Mason, T. L.; Tirrell, D. A. Macromolecules 1992, 25, 3601-3603.

(16) Perly, B.; Douy, A.; Gallot, B. Makromol. Chem. 1976, 177, 2569-2589.

(17) Douy, A.; Gallot, B. Polymer 1987, 28, 147-154.

(18) Klok, H. A.; Langenwalter, J. F.; Lecommandoux, S. Macromolecules 2000, 33, 7819-1826.

(19) Chen, J. T.; Thomas, E. L.; Ober, C. K.; Mao, G. P. Science 1996, $273,343-346$.

(20) Li, C.; Hsu, J. C.; Sugiyama, K.; Hirao, A.; Chen, W. C.; Mezzenga, R. Macromolecules 2009, 42, 5793-5801.

(21) Stasiak, J.; Squires, A. M.; Castelletto, V.; Hamley, I. W.; Moggridge, G. D. Macromolecules 2009, 42, 5256-5265.

(22) Klok, H. A.; Lecommandoux, S. Adv. Polym. Sci. 2006, 202, 75111.

(23) Floudas, G.; Papadopoulos, P.; Klok, H. A.; Vendermeulen, G. W. M.; Rodriguez-Hernandez, J. Macromolecules 2003, 36, 36733683.
(24) Hammond, M. R.; Klok, H. A.; Mezzenga, R. Macromol. Rapid Commun. 2008, 29, 299-303.

(25) He, C.; Zhao, C.; Chen, X.; Guo, Z.; Zhuang, X.; Jing, X. Macromol. Rapid Commun. 2008, 29, 490-497.

(26) Kania, C. M.; Nabizadeh, H.; McPhillimy, D. G.; Patsiga, R. A. J. Appl. Polym. Sci. 1982, 27, 139-148.

(27) Ludwigs, S.; Krausch, G.; Reiter, R.; Losik, M.; Antonietti, M.; Schlaad, H. Macromolecules 2005, 38, 7532-7535.

(28) Nakajima, A.; Kugo, K.; Hayashi, T. Macromolecules 1979, 12, 844-848.

(29) Yoda, R.; Komatsuzaki, S.; Nakanishi, E.; Hayashi, T. Eur. Polym. J. 1995, 31, 335-339.

(30) Rubatat, L.; Kong, X.; Jenekhe, S. A.; Ruokolainen, J.; Hojeij, M.; Mezzenga, R. Macromolecules 2008, 41, 1846-1852.

(31) Oh, S. B.; Choi, Y. K.; Cho, C. S. J. Appl. Polym. Sci. 2003, 88, 2649-2656.

(32) Agut, W.; Brûlet, A.; Taton, D.; Lecommandoux, S. Langmuir 2007, 23, 11526-11533.

(33) Cai, C.; Zhang, L.; Lin, J.; Wang, L. J. Phys. Chem. B 2008, 112, 12666-12673.

(34) Cho, C. S.; Kim, S. W.; Sung, Y. K.; Kim, K. Y. Makromol. Chem. 1988, 189, 1505-1510.

(35) Poché, D. S.; Moore, M. J.; Bowles, J. L. Synth. Commun. 1999, 29, 843-854.

(36) Dorman, L. C.; Shiang, W. R.; Meyers, P. A. Synth. Commun. 1992, 22, 3257-3262.

(37) Kricheldorf, H. R. $\alpha$-Amino Acid N-Carboxyanhydrides and Related Heterocycles; Springer-Verlag: New York, 1987.

(38) Block, H. Poly $(\gamma$-benzyl-L-glutamate) and Other Glutamic Acid Containing Polymers; Gordon and Brench: New York, 1983.

(39) Papadopoulos, P.; Floudas, G.; Klok, H. A.; Schnell, I.; Pakula, T. Biomacromolecules 2004, 5, 81-91.

(40) Elliott, A. Poly(R-amino acids): Protein Models for Conformational Studies; Fasman, G. D., Eds.; Marcel Dekker: New York, 1967.

(41) Luo, S.; Huang, C. Y. F.; McClelland, J. F.; Graves, D. J. Anal. Biochem. 1994, 216, 67-76.

(42) Holloway, P. W.; Mantsch, H. H. Biochemistry 1989, 28, 931935

(43) Dong, A.; Huang, P.; Caughey, W. S. Biochemistry 1990, 29, $3303-$ 3308.

(44) Surewicz, W. K.; Mantsch, H. H. Biochim. Biophys. Acta 1988, 952, $115-130$.

(45) Kauppinen, J. K.; Moffatt, D. J.; Mantsch, H. H.; Cameron, D. G. Anal. Chem. 1981, 53, 1454-1457.

(46) Susi, H.; Byler, D. M. Biochem. Biophys. Res. Commun. 1983, 115, 391-397.

(47) Kauppinen, J. K.; Moffatt, D. J.; Mantsch, H. H.; Cameron, D. G. Appl. Sprectrosc. 1981, 35, 271-276.

(48) Yang, W. J.; Griffiths, P. R.; Byler, D. M.; Susi, H. Appl. Spectrosc. 1985, 39, 282-287.

(49) Lecommandoux, S.; Achard, M. F.; Langenwalter, J. F.; Klok, H. A. Macromolecules 2001, 34, 9100-9111.

(50) Schlaad, H.; Smarsly, B.; Losik, M. Macromolecules 2004, 37, 2210-2214 